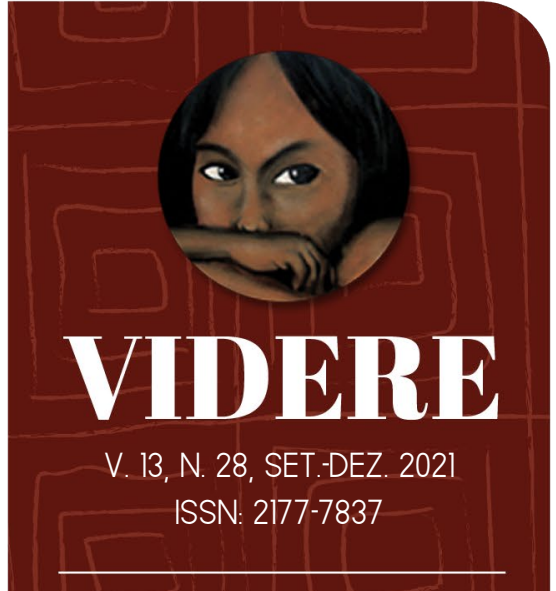

Recebido: 10/07/2021. Aprovado:27/09/2021.

Páginas: 437-461.

DOI: $10.30612 /$ videre. v13i28.11772

Univ. do Estado de Minas. pablo.coelho@uemg.br OrcID: 0000-0002-7374-2051

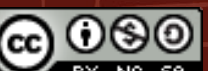

\section{Políticas públicas de distribuição de renda no Brasil}

Public policies for income distribution in Brazil

Políticas públicas para la distribución de ingresos en Brasil

\section{Pablo Martins Bernardi Coelho*}

\section{Resumo}

O trabalho em tela tem enfoque nas Políticas Públicas de Distribuição de Renda como instrumento para a efetivação de normas programáticas do texto constitucional, que constituem objetivos da República Federativa do Brasil. O trabalho contou com farta pesquisa bibliográfica, tanto de autores ligados ao Direito Constitucional, Direitos Humanos, Ciências Políticas e Antropologia, mostrando a multidisciplinariedade do tema. Através de tais escritos o trabalho traz conceitos teóricos de políticas públicas, bem como sua evolução histórica no Brasil. Posteriormente, mostra-se necessário o dever de reparação estatal através das Políticas Públicas de distribuição de renda eficientes, para que o viver com dignidade atinja materialmente todos os cidadãos, alcançando a almejada justiça social. As poucas políticas públicas de distribuição de renda implantadas no país são analisadas, como o Programa Renda Mínima, Bolsa Escola, Bolsa Família, bem como aqueles que possuem regulamentação, mas não foram implantados, como a Lei 10.835/2004.

Palavras-chave: Políticas públicas. Distribuição de renda. Renda básica de cidadania.

\begin{abstract}
The present work focus on Public Policies of Income Distribution as an instrument for the implementation of programmatic norms of constitutional text, which are objectives of the Federative Republic of Brazil. This work counted on a great bibliographical research, of authors related to Constitutional Law, Human Rights, Political Sciences and Anthropology, showing the multidisciplinarity of the theme. Through these writings, the work brings theoretical concepts of public policy, as well as its historical evolution in Brazil. After that, it is necessary to have a state reparation obligation through the efficient Public Distribution Policies, so
\end{abstract}


that living with materially dignity affects all citizens, achieving the desired social justice. The few public income distribution policies implemented in the country are analyzed, such as the "Programa Renda Mínima", "Bolsa Escola", "Bolsa Família", as well as those that have legal regulations but have not been implemented, such as the Law 10.835/2004.

Keywords: Public policy. Income distribution. Basic citizenship income.

\section{Resumen}

El trabajo en pantalla se centra en las Políticas Públicas de Distribución de la Renta como instrumento para la implementación de las normas programáticas en el texto constitucional, que son objetivos de la República Federativa de Brasil. El trabajo contó con una extensa investigación bibliográfica, tanto de autores vinculados al Derecho Constitucional, Derechos Humanos, Ciencias Políticas y Antropología, que muestra el carácter multidisciplinario del tema. A través de tales escritos el trabajo trae conceptos teóricos de las políticas públicas, así como su evolución histórica en Brasil. Posteriormente, se demuestra necesario el deber de reparación estatal a través de Políticas Públicas para la distribución eficiente del ingreso, para que vivir con dignidad afecte materialmente a todos los ciudadanos, logrando la justicia social deseada. Se analizan las pocas políticas públicas de distribución del ingreso implementadas en el país, como el Programa de Renta Mínima, Bolsa Escola, Bolsa Família, así como aquellas que tienen normativa, pero no se han implementado, como la Ley 10.835 / 2004.

Palabras clave: Políticas públicas. La distribución del ingreso. Renta basica de ciudadanía.

\section{INTRODUÇÃO}

O presente trabalho aborda as Políticas Públicas de Distribuição de Renda no Brasil, tendo em vista as disparidades econômicas e de oportunidades na nação, tendo como maior perspectiva de avanço no contexto social brasileiro a efetivação da Lei 10.835/04, que instituiu a Renda Básica de Cidadania (RBC).

A Constituição Federal de 1988 dispõe em seu artigo $3^{\circ}$, III que um dos objetivos da República Federativa do Brasil é erradicar a pobreza e a marginalização, bem como reduzir as desigualdades sociais e regionais. Após mais de três décadas de sua promulgação, o momento é pertinente para analisar a supracitada norma programática, verificando os avanços e retrocessos em relação à busca de sua eficácia.

A princípio discorre-se sobre o conceito de políticas públicas, bem como a relação entre essas (que agem como instrumentos de efetivação de normas programáticas) e as normas constitucionais, principalmente as previstas nos incisos do art. $3^{\circ} \mathrm{da}$ Constituição Federal.

Nesse ínterim, é traçado um comparativo entre os programas de renda mínima (aqueles que submetem os beneficiários a certas condições) e os programas de renda básica (via de regra não impõe condicionalidades), abordando os pontos positivos e negativos de cada um. 
O trabalho aborda os aspectos históricos das políticas sociais brasileiras, bem como as políticas públicas de distribuição de renda já experimentadas no Brasil, alguns programas que se desenvolveram no âmbito governamental local, bem como os de abrangência federal, como o PGRM (Programa de Garantia de Renda Mínima), Programa Bolsa Escola e Programa Bolsa Família, chegando à análise do cenário atual, que inclui o Auxílio Emergencial instituído através da Medida Provisória 937/2020. Também discorre sobre possíveis políticas públicas de distribuição de renda, tendo como maior perspectiva de avanço a efetivação da Lei $10.835 / 04$, que institui a Renda Básica de Cidadania (RBC).

A discussão acerca da temática da Renda Básica em âmbito Internacional é abordada, tratando desde seus aspectos históricos, até analises realizadas pela BIEN (Basic Income Earth Network), por Van Parjis, e por Eduardo Suplicy, estudiosos do teme que estimam que a Renda Básica de Cidadania, quando instituída universalmente, será tão relevante quanto a abolição da escravatura e a instituição do sufrágio universal.

Foi utilizado o método zetético, pois foram abordados aspectos críticos. O assunto é polêmico e demanda o uso do respectivo método, pois é mais adequado para buscar o conhecimento que foge ao dogmatismo do positivismo jurídico estrito. Além disso, o presente estudo será realizado por método de pesquisa exploratória, mediante o levantamento bibliográfico acerca do tema, sendo mapeadas as principais questões teóricas atinentes à temática. De acordo com (GIL, 2002) "a pesquisa exploratória proporciona maior familiaridade com um dado assunto, e são normalmente realizadas por meio de pesquisas bibliográficas”.

Quanto ao procedimento, essa pesquisa se caracteriza como pesquisa bibliográfica. Tal procedimento, afirmam Lakatos e Marconi (1999), abrange todas as publicações relacionadas ao tema estudado, desde publicações avulsas, revistas, livros, monografias etc., até meios de comunicação orais como rádios e gravações audiovisuais.

Desta feita a pesquisa não se restringe aos domínios das palavras, buscando atingir a realidade das coisas, visando constituir um instrumento para a ciência da realidade.

\section{POLÍTICAS PÚBLICAS E CONSTITUIÇÃo FEDERAL}

É relevante, antes de aprofundar nas ideias da temática em si, a compreensão conceitual e histórica das "Políticas Públicas" e a relação direta com a efetivação de normas constitucionais. Posteriormente ficará cristalino o objeto de estudo relativo às Políticas Públicas de Distribuição de Renda. 
Políticas públicas podem ser compreendidas como um instrumento que, através das relações de poder social, visam efetivar os direitos e garantias fundamentais de determinada nação.

A criação de uma determinada política pública tem como escopo enfrentar algum problema de natureza pública. Conforme definição de Thomas Dye, política é uma orientação à atividade ou à passividade de alguém; as atividades ou passividades decorrentes dessa orientação também fazem parte da política pública. (1972).

Desta feita, é correto dizer que políticas públicas possuem elementos fundamentais, destacando-se dois: solucionar um problema público e intenções públicas. Pode-se dizer que o objetivo da instauração de uma política pública é o enfrentamento de um problema relevante para a coletividade, buscando dirimi-lo ou erradica-lo.

Nesse sentido, as políticas públicas tem o condão de efetivar normas programáticas dispostas na Constituição Federal. Dentre as normas constitucionais de caráter programático que fundamentam as políticas públicas de distribuição de renda, destaca-se o art. $3^{\circ}$ da Carta Magna. Tal dispositivo da Constituição Federal de 1988 elenca alguns dos objetivos da República Federativa do Brasil: I - construir uma sociedade livre, justa e solidária; II - garantir o desenvolvimento nacional; III - erradicar a pobreza e a marginalização e reduzir as desigualdades sociais e regionais; IV - promover o bem de todos, sem preconceitos de origem, raça, sexo, cor, idade e quaisquer outras formas de discriminação.

Ademais, a Constituição da República Federativa do Brasil de 1988 é colocada de forma emblemática como um fruto de um processo de redemocratização e introdução de várias demandas sociais. Conforme definição dada por Ulysses Guimarães, uma “constituição cidadã”. Porém, na prática, houve uma transição com um pano de fundo conservador. De um lado, atores políticos que tinham o anseio de democratização plena, de outro os que almejavam a manutenção do regime autoritário de autarquia militar. Nesse contexto, a transição, em suas entrelinhas, foi um grande acordo entre esses dois polos. A transformação social subordinou-se às determinações do neoliberalismo e a herança do conservadorismo, causando prejuízos a implementação de efetivas políticas públicas que efetivem o texto constitucional.

Destarte, há estudos acerca das transições de regimes autoritários para democráticos nos continentes Americanos e Europeus. No que tange aos pactos políticos de redemocratização:

É evidente que o modo de transição deixa marcas importantes no funcionamento da democracia recém-estabilizada. Ainda que não seja o único fator ou mesmo o mais relevante para explicar as características do governo de suceder a transição, é inegável que em alguma medida que só poderá ser estimada empiricamente, contribui de maneira direta tanto para as potencialidades quanto para as deficiências que marcarão o regime democrático recém instituído. (QUINALHA, p. 15; 2013). 
Nota-se a discrepância entre o que fora determinado pela Carta Magna e o que realmente se efetivou, após mais de trinta anos de sua promulgação. O pacto democratizante demonstra que a recente democracia brasileira não ocorreu em bases sólidas, sendo necessário, portanto, ações que corroborem para que todos brasileiros vivam com dignidade.

A maximização da efetivação de direitos sociais, conforme Ianni (1998), pode promover uma maior politização dos indivíduos. Silva (2011), segue a mesma linha de raciocínio, entendendo que as políticas de distribuição de renda suprem carências materiais que impedem, até mesmo, o exercício da cidadania, conferindo-lhes meios para lutar pelas próprias demandas.

No Estado-liberal o direito à liberdade é considerado o de maior relevância. Tal garantia visa conter possíveis abusos de poder por parte do Estado, ou seja, está compreendido dentre os direitos humanos de primeira geração.

Já no Estado-social, embora o direito à liberdade tenha permanecido na íntegra, o direito a igualdade foi posto em debate com mais afinco, transpassando as barreiras da mera igualdade formal, sendo sua interpretação expandida para um sentido material, com a atuação positiva do Estado (direitos humanos de segunda geração), visando dirimir as desigualdades socioeconômicas.

Todavia, no Estado social, conquanto o direito à liberdade tenha permanecido íntegro, a relevância do direito à igualdade foi substancialmente acentuada, de tal sorte que o seu conceito passou a ter um sentido material, e não mais meramente formal. A garantia de igualdade no Estado social demanda, pois, atuação positiva, com a finalidade de reduzir as desigualdades socioeconômicas, mediante a distribuição equitativa de recursos. (CANELA JÚNIOR, p. 51; 2011).

Ladeado a isso, a democracia é, obrigatoriamente, ligada à proteção efetiva dos direitos fundamentais. Logo, se o Estado confere liberdade aos cidadãos, mas não executa políticas adequadas para proporcionar-lhes igualdade material, não pode ser considerado realmente democrático. A igualdade formal apenas, garante uma democracia meramente política, mas não social. Os indivíduos que estão à margem da sociedade perdem a própria consciência de cidadãos.

De fato, a igualdade substancial pressupõe condições materiais adequadas ao desenvolvimento do homem como cidadão, legítimo partícipe das decisões políticas. É indispensável que o homem não esteja sujeito a um grau de degradação material que lhe suprima a plena consciência de sua condição de cidadão. A miséria é incompatível com a lucidez exigida do cidadão, legítimo interveniente dos destinos do Estado, pois submete o ser humano a infame condição de mero sobrevivente sujeito às injunções biológicas básicas. (CANELA JÚNIOR, p. 52; 2011). 
Nesse viés, Josué de Castro também contribui definindo a fome e a miséria como a expressão biológica de uma doença política, econômica e social. Desta feita, o que se busca com a implementação de políticas públicas é traçar um caminho para efetivação de direitos sociais presentes na Constituição Federal, combatendo o ciclo vicioso da pobreza e da cidadania através de investimentos e estratégias políticas.

\section{PROGRAMAS DE RENDA MÍNIMA NO BRASIL}

\subsection{Do Programa de Garantia de Renda Mínima ao Programa Bolsa Família}

De maneira geral, a renda mínima pode ser caracterizada como o auxílio financeiro estatal recebido por pessoas em situação de pobreza e miséria, por um período de tempo limitado, que garante a esses indivíduos o mínimo necessário para uma existência digna. Sobre o assunto:

No Brasil de hoje, a ideia de garantir renda mínima a todos os residentes pode soar pitoresca, ou pior até. Quando direitos dados como certos são sistematicamente desrespeitados ou deixados caducar, quando grassam a ineficiência e a fraude no setor público, quando é tão ampla a crise e tão sérios são os problemas para gerar e alocar recursos sociais - há de causar estranheza à ideia de usar parte daqueles recursos para distribuir a quem produz pouco ou nada. (Frederico de Carvalho in Suplicy, 1992, p. 247).

A Renda Mínima possui alguns pressupostos, quais sejam: conhecimento dos recursos dos indivíduos a serem beneficiados; realização de testes de renda e de conhecimento sobre a situação das famílias, bem como de índices sociais e econômicos; enquadramento do beneficiário somente após o preenchimento de todos requisitos, ou seja, a renda só será complementada de acordo com as necessidades de cada indivíduo; medidas devem ser tomadas para se reduzir possíveis desestímulos ao trabalho e para reduzir o acesso ao benefício, por quem não faz jus.

$\backslash$ Mais adiante, a Carta Constitucional de 1988 trouxe o primeiro dispositivo legal a garantir uma renda mínima, no caso, aos maiores de 70 anos e portadores de deficiência, cuja renda familiar per capta não seja superior a um quarto do salário mínimo, conhecido como Benefício de Prestação Continuada (BPC). Além da Constituição Federal, tal dispositivo encontra-se disciplinado na Lei Orgânica de Assistência Social (LOAS), sendo regulamentado em 1993.

Nesse contexto pós transição, os poucos programas instaurados tiveram um caráter emergencial, afim de reduzir os mais vulneráveis à condição da miséria e extrema pobreza. Esses foram implementados de forma focalizada e residual. Visavam 
amenizar as mazelas, porém não tinham o condão de solucionar as causas da miséria.

É nesse cenário que, em 1991, o então Senador Eduardo Suplicy propõe o primeiro projeto de Renda Mínima (PGRM). A proposta foi elabora em conjunto com Silveira, o idealizador teórico da Renda Mínima no Brasil em 1975. A tentativa foi de trazer ao debate nacional uma proposta abrangente acerca da erradicação da miséria, além de regulamentar disposições e objetivos da nova constituição pela perspectiva das políticas públicas.

O Programa de Garantia de Renda Mínima, então, foi apresentado no Senado Federal em 16 de abril de 1991 como o Projeto de Lei $n^{\circ}$ 80, sendo aprovado pela Casa em 16 de dezembro do mesmo ano. De maneira geral, previa que aqueles indivíduos que não atingissem o nível de renda pré-fixado como o mínimo para subsistência seriam beneficiados por meio da negativação do imposto de renda, com diferença de $30 \%$ entre o valor pré-fixado e o valor da renda.

O PGRM surgiu em um momento de grande instabilidade nacional e internacional, se destacando pela originalidade e ousadia. Nesse sentido:

A despeito disso como programa pioneiro a proposta do PGRM foi de
grande ousadia para o cenário brasileiro, ainda mais se analisarmos o
período em que foi apresentada. O ano de 1991 foi o segundo do Gover-
no Fernando Collor de Mello, a inflação era um problema crônico, o
país vinha de um período recessivo que ainda se fazia presente, os ín-
dices de consumo eram muito baixos, o quadro era de corte de gastos
e as denúncias de corrupção e fraudes eram corriqueiras. A pobreza
e a desigualdade estavam em crescimento. O ambiente externo era de
acirramento do processo político-ideológico neoliberal com desmon-
te dos sistemas de Welfare State, colapso terminal da URSS (União das
Repúblicas Socialistas Soviéticas) e crise principalmente na América
Latina e na Ásia. (CARDOSO, p. 62; 2013).

A despeito do seu caráter revolucionário e dos altos índices de desigualdade existentes no país, o Projeto de Lei do PGRM, que fora aprovado pelo Senado Federal, encontra-se estacionado há mais de 20 anos na Câmara dos Deputados, aguardando votação, muito embora ainda persistam na realidade brasileira os motivos elencados pelo Senador Suplicy para elaboração do projeto. Todavia, ainda que tardiamente, se aprovado o PGRM será de extrema valia na busca pela redução de desigualdades sociais, ressalvando seu caráter supletivo a outros benefícios mais abrangentes, como o da Renda Básica da Cidadania, que será abordada oportunamente.

Não obstante o PGRM seja o programa pioneiro de Renda Mínima, ao longo dos anos outros programas surgiram no contexto social brasileiro, sendo alguns de caráter federal e outros de âmbito local. 
Pode-se citar como exemplo de programa de Renda Mínima no âmbito municipal o Programa de Garantia de Renda Familiar Mínima do Município de Campinas, aprovado em 1994 e implementado em 1995, consistente na distribuição monetária focada no combate à extrema pobreza. O programa inovou ao focalizar no conceito de extrema pobreza, ao dar atenção especial à saúde, ao ter limite de tempo de permanência e ao possuir um local específico de abrangência, qual seja, o Município de Campinas/SP. Sua concessão era condicionada ao preenchimento de uma série de requisitos e previa um valor de benefício baixo em relação ao proposto por Suplicy no PGRM.

Outro exemplo de programa em âmbito municipal é o Programa Bolsa Familiar para Educação do Distrito Federal, também iniciado em 1995, o qual beneficiava crianças e adolescentes de 7 a 14 anos com renda per capita familiar inferior à $1 / 2$ salário mínimo. Além desses, o benefício era condicionado a outros diversos requisitos, que dificultavam o seu acesso e eficácia.

Foram implantados outros programas na esfera municipal, como o Programa de Garantia de Renda Mínima de Ribeirão Preto, o Programa de Belo Horizonte, o Programa de Franca, o Bolsa Criança-Cidadã e o Programa de Jundiaí, todos nos moldes de Renda Mínima (Cardoso, 2013).

Lado outro, o primeiro programa de caráter nacional foi o Programa Nacional de Renda Mínima Bolsa Escola (PBE), aprovado em 1997 como a Lei no 9533/97 e sancionado pelo então Presidente da República Fernando Henrique Cardoso. Na realidade, não se tratava de um programa próprio, mas sim da padronização dos programas que já existiam nos municípios.

Em 2001 o Programa foi ampliado e passou a abarcar todos os municípios do país, além de estabelecer outras significativas mudanças, como se nota a seguir:

Em 2001 houve uma ampliação do programa sancionado pelo presidente Fernando Henrique Cardoso, o PBE passava a abarcar todos os municípios do país, a administração municipal foi padronizada, o benefício passou a ser fornecido através de um cartão magnético vinculado à Caixa Econômica Federal e pagos preferencialmente às mulheres. Além disso, o financiamento passou a ser totalmente de responsabilidade da União. A faixa etária foi ampliada para crianças de 6 a 15 anos que frequentassem a escola e com renda familiar per capita de $1 / 2$ salário mínimo. Os valores dos benefícios também mudaram passando a ser de $\mathrm{R} \$ 15,00, \mathrm{R} \$ 30,00$ ou $\mathrm{R} \$ 45,00$ dependendo do valor da renda per capita e do número de filhos. (CARDOSO, p. 160, 2013).

Outros programas federais foram sendo criados, como o PETI - Programa de Erradicação de Trabalho Infantil, criado em 1996, com o escopo de eliminar o trabalho infantil através do fornecimento de recursos financeiros às famílias em situação 
de miséria. Além desse, foi instituído o Programa Nacional de Renda Mínima Bolsa Alimentação (PBA), em 2001, visando a complementação de renda de famílias com crianças de 0 a 6 anos ou com gestantes, sendo incorporado pelo Programa Bolsa Família em 2003.

O Programa Fome Zero, programa federal de significativo destaque, previa um conjunto de ações para combater a fome e visava garantir a todos os cidadãos brasileiros três refeições diárias. Inicialmente, o benefício era auferido por meio do Cartão Alimentação, o qual tinha o valor $\mathrm{R} \$ 50,00$ (cinquenta reais) por família.

Conquanto todos os programas supracitados sejam de extrema importância na efetivação da Renda Mínima no país, o programa de maior expressividade e abrangência sem sombra de dúvidas é o Bolsa Família, vigente até os dias atuais, e que merece explanação em tópico específico a seguir.

O Programa Bolsa Família foi criado em 2003 através da Medida Provisória 132/2003, primeiro ano do governo do presidente Luís Inácio Lula da Silva, sendo a maior iniciativa de transferência de renda já vista no país. O programa unificou a maioria dos programas de transferência de renda existentes, como o Bolsa Escola, Bolsa Alimentação, Vale Gás e Vale Alimentação e do PETI (Programa de Erradicação do Trabalho Infantil).

No ano seguinte foi convertido na Lei $\mathrm{n}^{\mathrm{o}} 10.836 / 2004$, e regulamentado pelo Decreto $n^{\circ} .5209$ de 17 de setembro de 2004, o Programa Bolsa Família (PBF) é definido pelo Ministério de Desenvolvimento Social e Combate à Fome (MDS) como "um programa que beneficia famílias em situação de pobreza e extrema pobreza em todo o país”.

Segundo o Art. $4^{\circ}$, do Decreto n ${ }^{\circ}$ 5.209/04, o Programa Bolsa Família tem como objetivos promover o acesso à rede de serviços públicos, em especial de saúde, educação e assistência social; combater a fome e promover a segurança alimentar e nutricional, estimular o desenvolvimento das famílias beneficiárias e combater a pobreza.

De acordo com o MDS, o Programa Bolsa Família destina-se a todas as famílias com renda per capita de até $\mathrm{R} \$ 89,00$ (oitenta e nove reais) mensais ou às famílias com renda per capita entre $\mathrm{R} \$ 89,00$ (oitenta e nove reais) e $\mathrm{R} \$ 178,00$ (cento e setenta e oito reais), desde que tenham em sua composição crianças ou adolescentes de 0 até 17 anos.

O PBF prevê vários tipos de benefícios a depender da composição familiar e da renda da família beneficiária. Ao final, o valor total recebido pela família é a soma do benefício geral somado às variáveis previstas pelo programa. Assim, o Benefício Básico tem o valor de $\mathrm{R} \$ 89,00$ (oitenta e nove reais) e é pago apenas as famílias consideradas extremamente pobres (que tenham renda mensal por pessoa de até $\mathrm{R} \$ 89,00$ ). 
Já os benefícios variáveis, que podem ser de até cinco por família, são relativos à: crianças e adolescentes com frequência escolar regular; crianças de 0 a 6 meses, para reforçar a alimentação do bebê; gestantes que fizerem o acompanhamento regular através do SUS.

Além desses, o programa ainda prevê o Benefício Variável Vinculado ao Adolescente, no valor de $\mathrm{R} \$ 48,00$ (até dois por família), pago às famílias com renda mensal de até $R \$ 178,00$ por pessoa e que tenham adolescentes entre 16 e 17 anos em sua composição, exigida a frequência escolar dos adolescentes, e o Benefício para Superação da Extrema Pobreza (individual por família), pago às famílias que continuem com renda mensal por pessoa inferior a $\mathrm{R} \$ 89,00$, mesmo após receberem os outros tipos de benefícios do Programa. Nesse benefício, o valor é calculado caso a caso, de acordo com a renda e a quantidade de pessoas da família, para garantir que a família ultrapasse o piso de $\mathrm{R} \$ 89,00$ de renda por pessoa.

O Programa Bolsa Família, o qual possui papel fundamental em reforçar o acesso das famílias à educação e à saúde, é concretizado por meio de alguns compromissos, chamados condicionalidades. Tais condicionalidades são de responsabilidade dos beneficiários e também do Poder Público, que tem o dever de garantir às famílias beneficiadas a oferta e qualidade dos serviços disponíveis pelo programa. Nesse sentido:

O Programa Bolsa Família configura - se como um programa de transferência direta de renda com condicionalidades, estabelecendo um vínculo entre o recebimento do benefício ao cumprimento de um conjunto de compromissos assumidos tanto pela família quanto pelo poder público para ampliar o acesso dessas famílias a seus direitos sociais básicos. Por um lado, as famílias devem assumir e cumprir esses compromissos para continuar recebendo o benefício; por outro, as condicionalidades responsabilizam o poder público pela oferta dos serviços públicos de saúde, através do acompanhamento de crianças, mulheres e gestantes; de educação, com a exigência de boa frequência escolar e da assistência social, através da inclusão de crianças e adolescentes em outros programas sociais, como por exemplo o PETI (Programa de Erradicação do Trabalho Infantil). (MACHADO SILVA, p. 64; 2014)

$\mathrm{Na}$ área da educação, são condicionantes: os responsáveis devem matricular as crianças e os adolescentes de 6 a 17 anos na escola e a frequência escolar deve ser de, pelo menos, 85\% das aulas para crianças e adolescentes de 6 a 15 anos e de $75 \%$ para jovens de 16 e 17 anos, todo mês.

Já na área da saúde, o programa define como condicionantes que os responsáveis levem as crianças menores de 7 anos para tomar as vacinas recomendadas pelas equipes de saúde e para pesar, medir e fazer o acompanhamento do crescimento e do desenvolvimento, e que as gestantes devem fazer o pré-natal e ir às consultas na Unidade de Saúde. 
A fiscalização dessas condicionantes fica a cargo dos três níveis de governo, quais sejam, federal, estadual e municipal, que trabalham em conjunto para acompanhar os compromissos assumidos pelos beneficiários do Bolsa Família. Para tanto, é efetuado o registro, em sistemas específicos, de informações sobre a frequência escolar e sobre a agenda da saúde dos beneficiados, sendo o monitoramento realizado de maneira individualizada.

Destarte, todos esses métodos de fiscalização garantem que o poder público ofereça de maneira efetiva os serviços de educação e de saúde à população em situação de extrema pobreza, bem como identifique as famílias que possuam dificuldade para acessar tais serviços, encaminhando-as para a rede de assistência social a fim de que superem tais vulnerabilidades e voltem a utilizar o programa devidamente, cumprindo seus compromissos.

Como dito, o PBF obedece a um sistema de condicionantes, de maneira que, diante de seu descumprimento, serão aplicados efeitos gradativos. Inicialmente, é dada ao beneficiário desidioso uma advertência, que não afeta o recebimento do benefício. Caso o descumprimento se repita dentro de um período de até seis meses, haverá o bloqueio do benefício, impedindo que as famílias o recebam por um mês, embora esse valor possa ser sacado posteriormente. Se, após o bloqueio, houver novo descumprimento em até seis meses, o benefício ficará suspenso por dois meses, sem que a família possa reaver o valor dessas parcelas. Por fim, como efeito mais gravoso, há o cancelamento do benefício, aplicado excepcionalmente, uma vez que o descumprimento reiterado das condicionantes, na grande maioria, significa uma situação de vulnerabilidade da família, devendo essa passar por um acompanhamento pela área de assistência social do município, antes de serem desligadas efetivamente do programa.

Apesar de ser um programa de caráter federal, para que o PBF funcione efetivamente, é de suma importância a conjugação de esforços de todos os entes públicos, sendo a União, os Estados, o Distrito Federal e os Municípios corresponsáveis pela implementação do programa. Nesse sentido, de acordo com o MDS “a gestão do Bolsa Família é descentralizada, com competências específicas para cada ente da Federação, mas sempre articuladas”.

Enquanto se consolida e se desenvolve no contexto social brasileiro, o Programa Bolsa Família ganha relevante significado social, destacando-se e expandindo o cenário político e econômico brasileiro como uma das mais importantes estratégias de enfrentamento à pobreza do país. Há praticamente um consenso de que o PBF promoveu o alívio imediato da pobreza por meio da transferência direta de renda à população socialmente vulnerável.

Em contrapartida a esse processo expansivo, o Programa Bolsa Família vem sendo alvo de diversas críticas quanto a seu desenvolvimento, mormente no que diz 
respeito ao seu desempenho no alcance dos objetivos delineados no programa.

Uma das principais críticas é quanto ao modo como é feita a seletividade do público alvo a ser beneficiado pelo programa. Isto porque, essa é uma característica totalmente oposta ao caráter universal dos direitos sociais e ao próprio aspecto de proteção social que o programa se compromete, uma vez que deixa de atingir grande parte da população que se encontra em situação de pobreza e extrema pobreza.

Embora a renda seja um elemento essencial para identificação da pobreza, outros fatores precisam ser considerados, como o acesso a bens, recursos e serviços sociais e outros meios complementares de sobrevivência. Assim, a pobreza é compreendida pelo programa apenas como a deficiência ou ausência de renda, não sendo analisada como o verdadeiro fenômeno histórico e social que é. Nesse sentido:

Partindo dessa análise do Programa Bolsa Família sobre a concepção de pobreza, é possível perceber o quão limitado, focalizado e compensatório o mesmo vem se tornando ao longo dos seus dez anos de surgimento, evidenciando as dificuldades e os desafios que o programa precisa superar, enquanto instrumento de enfrentamento à pobreza. (MACHADO SILVA, p.68, 2014).

Dessa forma, é possível concluir que o Programa Bolsa Família apresenta problemas estruturais relevantes que limitam a inclusão de parte da população, também considerada pobre, reduzindo as possibilidades de impactos mais significativos no que diz respeito à redução dos índices de pobreza no país.

Outro ponto importante a ser aludido é a utilização do programa em favor de interesses políticos e econômicos, uma vez que vem sendo utilizado constantemente em campanhas políticas como instrumento de obtenção de voto e força política, seja pela garantia de sua manutenção, seja pela promessa de finalizar o programa.

Critica-se, também, a existência de tantas condicionantes para concessão do benefício uma vez que, embora tenham sido estabelecidas com o objetivo de contribuir para o acesso a serviços sociais básicos como saúde e educação, são vistas por muitos como um fator limitante que dificultaria o acesso da população ao benefício. Assim, entende-se que as condicionalidades são potencialmente segmentadoras e geram estigmas, na medida em que submetem aqueles que necessitam do benefício ao cumprimento de diversas obrigações. Sobre o assunto:

Esse paradoxo remete às antigas Leis dos Pobres, descaracterizando a perspectiva de cidadania ampliada, em que os direitos sociais são tratados como conquistas e não como concessão condicionada, bem como não problematiza questões fundamentais: a ausência da renda do trabalho - gerada estruturalmente e não conjunturalmente - não decorre de suposta incapacidade intelectual e/ou técnica dos indivíduos; a evasão escolar não representa uma escolha pessoal, pois em 
ampla medida é imposta por inúmeros fatores socioeconômicos de natureza estrutural; a precariedade e/ou inexistência de bens e serviços sociais públicos, os quais se convertem em obrigações, são impedimentos concretos ao acesso para toda a população. (GUILHERME, p. 213, 2016).

Todavia, a maior crítica realizada ao programa, consiste nos possíveis efeitos de acomodação que o programa poderia instigar nas famílias beneficiárias, crítica esta realizada por alguns estudiosos do programa e também, em grande parte, pela própria população que não se utiliza do benefício, sob a égide de que o programa incentivaria a população beneficiária a não buscar emprego, já que possuem uma renda sem esforço próprio, advinda do Estado.

Embora tal crítica seja pouco fundamentada, já que o benefício oferecido pelo programa é ínfimo ante todos os parâmetros de vida digna, não afastando a necessidade de geração de renda própria, uma saída para evitar essa remota consequência seria a articulação do PBF com outras políticas sociais, além da saúde, educação e assistência, mas também na área de habitação, lazer, esporte e principalmente no campo de geração de empregos e renda, possibilitando a entrada dos beneficiários no mercado de trabalho.

A despeito de todas as críticas supracitadas, é inegável que o Programa Bolsa Família atinge uma grande parcela da população que vive em situações de precariedade, retirando essas pessoas da condição de extrema pobreza e garantindo-lhes segurança alimentar e condições mínimas de sobrevivência.

Em artigo publicado no site Le Monde Diplomatique em 04 de agosto de 2008, Francisco Menezes e Mariana Santarelli afirmam que:

É preciso compreender o real significado do Bolsa Família. O programa está inserido em uma política social mais ampla, destinando-se especificamente a transferir renda para quem não tem nada ou muito pouco, satisfazendo necessidades básicas que não se limitam à alimentação. A complexidade da pobreza no Brasil precisa ser enfrentada com múltiplas iniciativas nas diferentes esferas e níveis do governo. O que não podemos exigir é que o programa faça as vezes das demais políticas sociais. Afora a garantia das políticas universais de educação e saúde, o grande desafio será conseguir articular o Bolsa Família com outras ações. Algumas complementares, que contribuam para a aquisição de direitos, e outras de caráter emancipatório. (MENEZES e SANTARELLI, 2008)

Conclui-se, assim, que muitos limites e grandes desafios devem ser enfrentados pelo programa e que superá-los significa romper com as barreiras que o capitalismo impõe a sociedade brasileira. Pode-se dizer que o Programa Bolsa Família consiste em um grito de cidadania, autonomia e esperança das camadas mais baixas da população. 
Suplicy (2013) analisa o sucesso do Programa Bolsa Família no combate à fome e à erradicação da pobreza, mas alerta que ele é apenas o primeiro passo para a implantação da Renda Básica de Cidadania - RBC.

\subsection{Auxílio Emergencial - MP 937/2020}

A última política pública de distribuição de renda instituída no Brasil foi o Auxílio Emergencial, criada para minimizar, de forma provisória, as dificuldades e necessidades causadas pela pandemia do COVID-19.

A medida foi oficializada através da Medida Provisória 937/2020, que abre crédito extraordinário, em favor do Ministério da Cidadania, no valor de R\$ 98.200.000.000,00 (noventa e oito bilhões e duzentos milhões de reais) destinadas a pessoas em situação de vulnerabilidade.

O valor do auxílio é de $\mathrm{R} \$ 600,00$ (seiscentos reais) por pessoa e de $\mathrm{R} \$ 1.200,00$ (um mil e duzentos reais) para mães solteiras. Mais uma vez o governo optou por impor condicionalidades aos beneficiários contemplados. Tem direito ao auxílio os maiores de idade em que a renda familiar per capta seja inferior a meio salário mínimo e não ultrapasse três salários mínimos no total. Os trabalhadores informais, autônomos e microempreendedores individuais (MEI) também tem direito ao benefício, desde que não tenham recebido rendimentos tributáveis acima de R\$28.558,70 em 2018.

Os trabalhadores formais não tem direito ao benefício, nem os aposentados, os que gozam de auxílio-doença, e os que recebem qualquer benefício do governo, salvo beneficiários do Programa Bolsa Família.

Impor condicionalidades em uma situação como essa não demonstra ser a melhor alternativa. Trabalhadores formais que tiveram drásticas reduções em seus salários não precisam tanto quanto, ou, em determinados casos, até mais do que os que se enquadram nas condições impostas? Um vendedor, por exemplo, que aufere a maioria da sua renda através de comissões das vendas, com as lojas temporariamente fechadas, não faz jus ao auxílio emergencial pura e simplesmente por encontrar-se no mercado formal?

Ademais, a somatória de esforços para determinar quem faz jus ou não ao auxílio é gigantesca, e não consegue apurar os realmente necessitados, pois baseiam-se apenas em formalidades e nem sempre o cruzamento de dados ocorre de forma eficiente.

Como se não bastasse, os entraves burocráticos e as falhas tecnológicas demandam um lapso temporal que fogem ao objetivo do programa, que é justamente ser um auxílio emergencial para que os vulneráveis socialmente tenham itens básicos de alimentação e higiene. 
A Folha de São Paulo publicou uma matéria abordando tais entraves, destacando que trata-se de um triste exemplo da diferença entre formulação e implementação de políticas públicas:

As repetidas filas e aglomerações nas agências da Caixa são os retratos de problemas de implementação, tais como funcionamento inadequado do aplicativo ou do portal da Caixa ou ainda as dificuldades de uso da tecnologia por parte dos cidadãos. Além desses problemas, muitas pessoas, embora elegíveis, poderão não receber as parcelas adicionais, tanto por falha na operacionalização quanto pelo fato de que quem desenhou o programa, aparentemente, ignorou o calendário contábil. Parafraseando Pressman e Wildavsky (1973), no clássico livro Implementation que analisou os problemas de implementação de políticas: um grande anúncio em Brasília pode se transformar em uma decepção nas filas da Caixa.

A política pública em si é válida, mas as condicionalidades impostas parecem contradizer os objetivos que a medida traz em seu bojo. Por outro lado, os avanços em relação ao montante de dinheiro destinado ao programa e a maior abrangência de beneficiários em relação a programas anteriores, geram expectativas positivas e pode trazer bons resultados no âmbito econômico e social. É válido lembrar que o Bolsa Família, incialmente, também foi instituído por uma Medida Provisória.

Em matéria publicada no site Le Monde Diplomatique no dia 29 de abril de 2020, Leandro Teodoro Ferreira, presidente da Rede Brasileira de Renda Básica, afirma:

O coronavírus tornou a humanidade testemunha de mudanças imediatas que poucas gerações presenciaram. Para a renda básica, que pertencia ao rol de utopias que sempre precisaram se defender contra a acusação de se tratarem de uma excentricidade, foi aberta uma via expressa para avançar sem que esteja certo o destino final dessa jornada. $O$ tensionamento político no qual estamos imersos mantém em aberto o futuro da proteção social. O que temos como certo é que esse futuro deve deixar para trás o estado de normalidade anterior. Uma renda básica, universal, incondicional e permanente pode estar no horizonte de quem se preocupa com a cidadania, a dignidade e a liberdade humana. (FERREIRA, 2020)

Desta feita, o momento atual causado pelo Covid-19 e o consequente isolamento social, evidencia a relevância da Renda Básica, pois demonstra sua versatilidade para atingir as mais variadas dimensões de carências e privações que os seres humanos estão sujeitos. 


\section{RENDA BÁSICA DE CIDADANIA}

\subsection{Perspectivas Históricas da Renda Básica}

Há muito tempo a ideia essencial da Renda Básica está inserida no pensamento de muitos teóricos, que vislumbravam a uma boa vida e assistência social, desde o século XVI. No entanto, essas contribuições ocorreram de forma esparsa, por isso não foram o suficiente para se solidificarem e darem a abrangência devida à temática. É no final do século XX, com a criação da BIEN (Basic Income European Network), que um grupo organizado de intelectuais passaram a empreender seus esforços nesse sentido.

A primeira menção a uma renda devida a todos os cidadãos de uma comunidade foi elaborada por Thomas More, em seu livro Utopia no ano de 1516, o livro é inspirado em outra obra clássica "A República” de Platão. More vislumbrava uma república ideal, propondo uma garantia de renda a todos os cidadãos como medida de combate à criminalidade, substituindo a pena de morte:

Ao invés de infligir estes castigos horríveis, seria muito melhor prover a todos algum meio de sobrevivência, de tal maneira que ninguém estaria se submetendo a terrível necessidade de se tornar primeiro um ladrão e depois um cadáver. (MORE, 2004; p. 70)

Outro teórico que contribuiu no passado foi um amigo de Thomas More, Johannes Ludovicus Víveres, professor em Oxford. Ele formulou um projeto de assistência aos necessitados da época, com financiamento oriundo de doações privadas a serem destinadas a todos os pobres. A distribuição ficaria a encargo dos poderes municipais.

Já outra etapa histórica da Renda Básica, que pode ser denominada de "Fase Moderna”, surge em meados do século XIX e representa as ideias iniciais do Welfare State, tendo grande impulsão com inspirações do modelo Bismarkiano, desenvolvido na Prússia. (CARDOSO, 2013).

$\mathrm{Na}$ Inglaterra o debate também teve início com o surgimento do Welfare State. Nesse período dois relatórios importantes foram formulados, um diagnóstico elaborado pela Comissão Real de Assistência aos pobres e o Relatório Beveridge.

Porém, o termo Básic Income (Renda Básica) surge no ano de 1934 em textos de Jan Tinbergen. James Meade, Prêmio Nobel, idealizou e defendeu uma proposta de dividendo social em seu livro "Esboço de governo econômico para um governo trabalhista”, de 1935. Sobre o assunto: 
Sem dúvida durante a primeira metade do século XX foi a Inglaterra o principal centro de desenvolvimento de ideias e debates referente à proteção social. Mas na Europa continental houve alguns ícones importantes, assim como em muitos outros lugares pelo mundo. $\mathrm{Na}$ França representados por Josef Popper-Lynkeus "Devoir de nourrir" [Dever de alimentar] de 1912, Jacques Duboin "La grande releve dês hommes par la machine" [A grande revelação dos homens para a máquina] 1932 e Alexandre Marc, "Redécouverte du minimum vital garanti" [Redescobrindo o mínimo vital garantido] 1972. Nos Estados Unidos Robert Theobald foi defensor da adoção de uma Renda Básica na década de 60. (CARDOSO, p.103; 2013).

Em muitos dos estudos da segunda metade do século XX os conceitos de Renda Básica e Renda Mínima se mesclavam. Nesse período surgem diversas iniciativas pela Europa, as mais abrangentes se deram nos países nórdicos. Durante a elaboração de programas de renda mínima, os debates tomavam rumos amplos, com caráter universal, conceitos que se aproximavam da Renda Básica. Nesse sentido, os que compactuavam com os ideais da Renda Básica, se engajaram e se organizaram. Nesse contexto iniciaram os debates em relação a criação do grupo da BIEN, que afastou a inércia existente e se esforçou para adicionar a Renda Básica no debate mundial.

\subsection{0 grupo da BIEN}

O grupo BIEN foi idealizado e fundado por pesquisadores e ativistas interligados por um objetivo em comum: os princípios da Renda Básica. A princípio o grupo estava relacionado com a Universidade de Louvain, na Bélgica, e se chamava "Coletivo Charlie Fourier”. O grupo ganhou prêmios na década de 80. Em 1986 membros do grupo elaboraram a criação da BIEN, que, na época, significava: Basic Income European Network, com o objetivo de solidificar uma rede de estudos do tema. A temática foi se expandindo e ganhando a atenção de pesquisadores em vários lugares do mundo, o que levou a alteração do significado BIEN, que passou a se referir não somente a Europa, mas a todo mundo: Basic Income Earth Network.

Philippe Van Parjis, um dos intelectuais mais prestigiados do grupo, engajou-se na causa quando, em 1982, ao desenvolver uma análise sobre a perspectiva política econômica e social, bem como as estruturas básicas em que a sociedade estava se construindo. Os resultados, na maioria das vezes, se davam em torno de fatores econômicos, porém, ao inserir o debate ambiental nesse contexto surgiram empecilhos: quais as consequências do crescimento econômico acelerado em todos os países? Como diminuir o crescimento de forma organizada? De que maneira equilibrar a diminuição do crescimento com a concorrência internacional? 
O socialismo real, em crise, tinha perdido, na prática, a possibilidade de um mundo com justiça social. A esquerda submersa em declínio, não apresentava perspectivas reais de progredir. Nesse contexto, passaram a averiguar a possibilidade de adaptar as engrenagens do capitalismo com os objetivos do socialismo. Posteriormente, a busca não era para construir, dentro do capitalismo, um caminho para o comunismo, mas sim a busca real por justiça social dentro do próprio capitalismo. Foi nessas circunstâncias e conjunturas que Van Parjis, junto com a BIEN, engajou-se na luta pela Renda Básica.

\subsection{Renda Básica de Cidadania: a visão da BIEN}

Van Parjis, bem como a BIEN, definem a Renda Básica como o valor pago individualmente a todos os cidadãos. $O$ pagamento é realizado por uma determinada comunidade política, independentemente da situação financeira e sem condicionalidades impostas aos indivíduos.

A Renda Básica é comparada por Van Parjis com a instituição do sufrágio universal, que para muitos parecia um ideal longe de ser colocado em prática, mas atualmente nota-se que em grande parte do Ocidente já se caracteriza como um direito fundamental.

Muitos defensores e intelectuais da BIEN relacionam o direito à renda incondicionada ao direito de todos gozarem do meio ambiente devidamente equilibrado, e estimam que quando for instituída de maneira universal poderá ser comparada aos sentimentos e benesses da abolição da escravatura. Também pode ser compreendida como uma forma de os trabalhadores buscarem empregos com melhores condições, não se submetendo a situações degradantes.

A distribuição equitativa e universal é positiva tanto para os pobres quanto para os ricos. Para os últimos a renda de cidadania lhes confere maior grau de segurança pública, pois à medida que as classes menos favorecidas economicamente passam a ter mais dignidade e cidadania, a tendência é a queda dos índices de criminalidade. Já para os pobres é importante para afastar o estigma em relação aos beneficiários, transpassam o conceito de benefício, alcançando um patamar de direito de cidadania. Além disso, as pessoas mais pobres podem buscar se qualificarem e buscar empregos cada vez melhores, pois alcançar certo patamar de renda não significa o término do benefício.

\subsection{Renda Básica de Cidadania no Brasil: a visão de Suplicy}


Após a análise das propostas e programas de Renda Mínima, é momento de verificar a proposta mais recente de transferência de renda, elaborada por Eduardo Suplicy: a Renda Básica de Cidadania. Por muitos considerada uma ideia insana, inexequível; por outros considerada o melhor instrumento para a efetivação da tão almejada justiça social.

[...] é impossível pensar hoje em dia no futuro da proteção social, tanto na Europa quanto no resto do mundo, sem recordar o abono universal, ou seja, a ideia de pagar a todos os cidadãos, de forma incondicional, uma renda básica, cumulativa com qualquer outra (Van Parijs e Vanderborght, 2006, p. 29).

A Renda Básica de Cidadania (Lei 10.835/04) foi proposta por Suplicy e aprovada no Congresso no ano de 2001, sendo sancionada no dia 8 de janeiro de 2004.

Diferente da renda mínima, que foca sua ação nos mais vulneráveis socioeconomicamente e, na maioria dos casos, exige condições para o recebimento do benefício, a renda básica ocorre de forma universal, ou seja, todos os cidadãos possuem o direito de receber o valor correspondente ao benefício. Porém, a Lei que prevê a Renda Básica no Brasil traz peculiaridades quanto ao conceito da BIEN (Basic Income European Network).

A legislação brasileira dispõe que é direito de todo cidadão brasileiro residente no país e a todos os estrangeiros residentes há pelo menos cinco anos, não importando sua condição socioeconômica, receberem, anualmente, um benefício monetário. O programa deverá entrar em vigor por etapas, a critério do poder Executivo, seguindo as possibilidades econômicas do país e a Lei de Responsabilidade Fiscal. Sua implantação deve dar prioridade, inicialmente, às camadas mais necessitadas da população.

São vários os fundamentos elaborados para justificar a maior eficácia dos programas de distribuição de renda incondicionada: 1) Elimina a burocracia envolvida; 2) Acaba com o estigma existente em relação aos beneficiários de programas como o Bolsa Família; 3) Estimula as pessoas a procurarem outras fontes de renda, pois é cumulável, ou seja, não desaparece quando o beneficiário adquire outra forma de renda; 4) É um instrumento de combate a incerteza, favorecendo a dignidade e a liberdade humana; 5) Não é um programa assistencialista ou transitório; 6) Estimula o desenvolvimento de atividades não reconhecidas no mercado, bem como trabalhos voluntários, filantrópicos, voltadas ao cuidado do lar ou de assistência social; 7) Aumenta a competitividade da economia.

O programa está em consonância com os ideais de justiça social, igualdade, liberdade, fraternidade, solidariedade e democracia. No entanto, Suplicy destaca que outras medidas e programas sociais são fundamentais, como saúde, educação, reforma agrária, saneamento e estimulo a formas cooperativas de produção (2013). 
Suplicy coaduna com a ideia que o benefício deve ser monetário, pois outros métodos de assistência (como doação de cestas básicas) estão mais expostos a uso políticos e desvios indevidos de recursos. Já a fiscalização da renda monetária é mais transparente, além de conferir maior liberdade aos usuários, que podem fazer suas escolhas de acordo com as suas necessidades.

Outro aspecto importante é o caráter universal, ou seja, para todos. Para diagnosticar algum beneficiário do Programa Bolsa Família, por exemplo, é preciso realizar uma triagem complexa e minuciosa para saber se atende as condições socioeconômicas impostas. Nesse cenário, em muitos casos a pessoa é pobre, vive em condições de miséria, mas possui um rendimento que extrapola, em poucos reais, os limites impostos pelas condicionantes do programa, fazendo com que a pessoa se sinta lesada.

Além de diminuir os esforços na fiscalização e diagnóstico dos beneficiários, a Renda Básica alcança em maior escala e de forma mais prática os pobres. Os que detêm maior poder aquisitivo também tem direito ao benefício, o que contribui para que não haja estigmas, humilhações e segregações. É comum o surgimento desse estigma a beneficiários de programas focalizado nos mais pobres, como o Bolsa Família, por exemplo, que é chamado de "Bolsa esmola", "Bolsa vagabundo", dentre outros termos pejorativos.

Muitos questionamentos acerca da Renda Básica têm relação com um possível estímulo ao desemprego, porém, Suplicy aponta a política pública em tela como instrumento de combate à armadilha da pobreza ou possível desincentivo ao trabalho que os demais programas proporcionam. Nos programas tradicionais implementados até então, qualquer adicional na renda formal da família/indivíduo pode significar o rompimento do benefício. Nesse ponto:

Portanto, a Renda de Cidadania faz sempre valer o esforço do trabalho. Uma vez que a pessoa possa manter o valor integral de sua renda básica, esteja empregada ou não, sua situação será melhor quando estiver trabalhando do que desempregada (Suplicy, 2013, p. 22).

Nos debates que ocorreram na década de 90, Suplicy mencionava o trabalho como forma de valor, autonomia e dignidade ao cidadão, um processo pelo qual este se torna útil a sociedade, sendo um anseio pessoal de todos, não é apenas uma atividade geradora de renda (1992). Em sua visão, os afortunados financeiramente continuam trabalhando, mesmo tendo suas necessidades atendidas, pois é intrínseco ao ser humano almejar o progresso, e isso não é diferente nas famílias carentes de recursos.

Má sorte para os preguiçosos: eles receberão uma pequena renda. $\mathrm{O}$ dever da sociedade não vai além de prover a cada pessoa uma participação justa naquilo que a natureza colocou à sua disposição, sem usurpar o dinheiro de cada um (Fourieur in Suplicy, 2006, p. 38). 
Além do mencionado, a Renda Básica é útil para subsidiar ofícios e labores que são significativos e não são reconhecidos, ou seja, negligenciados. Alguns exemplos são: atividades voluntárias, atividades de manutenção do lar, cuidado com idosos e recém-nascidos, etc.

\subsection{Renda Mínima X Renda Básica}

Nesse contexto, a partir dos aspectos supra analisados é possível visualizar as divergências entres os programas de Renda Mínima e Renda Básica. O PGRM e o Programa Bolsa Família são exemplos de programas de Renda Mínima, logo possuem uma série de condicionalidades, já a Renda Básica é incondicionada e abrange toda uma comunidade política.

Os programas de Renda Mínima, em análise rasa, demonstram uma eficácia maior, pois a proposta proporciona uma estimativa de valores mais palpável e sua implementação aparentemente é mais rápida. Porém, ela implica em um nível maior de esforços em diagnosticar aqueles que se enquadram ou não nas imposições do programa, além da complexa dificuldade de realizar sua fiscalização, o que causa transtornos administrativos e operacionais.

A Renda Básica possui maior ímpeto de combate à desigualdade, já que teria a participação das classes mais altas e consequentemente o valor do auxílio seria maior. Por isso é que os ricos receberão a renda, mas também contribuirão com mais, pagando seu próprio benefício, como o de muitos outros. (Suplicy, 2006).

Desta feita, a Renda Básica aparenta ser mais combativa em dirimir as gritantes desigualdades sociais da nação, pois visa estabelecer patamares maiores de dignidade e cidadania, além de distanciar o estigma da pobreza em relação aos beneficiários.

Embora a Renda Mínima tenha suas benesses, pois impõe condições que conduzem os beneficiários a outras políticas públicas, como de saúde e educação, as condicionalidades impostas, muitas vezes, são armadilhas da pobreza. O programa Bolsa Família, por exemplo, ao impor um limite de rendimentos aos beneficiários pode desestimular que os membros da casa a entrar no mercado de trabalho formal, pois ao cruzar os dados e detectar a renda um pouco acima do limite extingue-se o benefício.

Nesse cenário, o núcleo familiar fica refém das condições impostas pelo programa, pois o emprego formal de um dos familiares, mesmo que ultrapasse em poucos reais o limite estabelecido, pode resultar na perca dos demais benefícios. Desta maneira, torna-se mais atrativo o mercado informal, que mantém o indivíduo na situação de vulnerabilidade social. 


\section{CONSIDERAÇÕES FINAIS}

As políticas públicas têm como condão solucionar um problema público, nessa esteira, no decorrer do trabalho ficam evidentes os problemas que justificam a implementação de políticas públicas de distribuição de renda, que são elementares para o alcance da paz social.

Como visto no decorrer da pesquisa, as políticas públicas de distribuição de renda visão erradicar um problema crônico da sociedade brasileira que é a gritante desigualdade de recursos e oportunidades, fruto de estruturas doentias herdadas de um passado marcado pela constante exploração dos mais vulneráveis

A Constituição Federal de 1988 trouxe em seu bojo vários direitos sociais, tornando-se uma "Constituição Cidadã”. O artigo terceiro em que elencou como objetivo da república a erradicação da pobreza, miséria e da marginalização, bem como reduzir as desigualdades sociais e regionais, trouxe a esperança da erradicação da miséria e redução da enorme desigualdade social, porém os avanços foram pequenos, insuficientes para erradicar a miséria.

Os programas até então implementados no Brasil, foram programas de renda mínima, que tem como características principais a focalização e a imposição de condicionalidades. As condicionalidades têm prós e contras, um dos aspectos positivos é conduzir as populações vulneráveis ingressarem em outras políticas públicas, efetivando, assim, outros direitos básicos, como o acesso a saúde, educação, e assistência social. Porém, a imposições de condicionalidades gera uma somatória de esforços para diagnosticar a população em vulnerabilidade bem como a complexa fiscalização do cumprimento das condições causando transtornos na administração e operacionalização do sistema de assistência social, vide o recentemente instituído Auxílio Emergencial.

Já a focalização, é prejudicial pois direciona o foco dos programas apenas às famílias em condição de miserabilidade, levando a estigmatização dos beneficiários, como ocorre atualmente com o programa família, que é alvo de discursos reacionários como "bolsa-esmola", "bolsa-vagabundo", dentre outros termos pejorativos.

A renda mínima ainda traz a possibilidade de transformar-se em armadilha da fome para alguns beneficiários, pois estes podem optar por trabalhos no mercado informal, mesmo que estes sejam degradantes e em condições desumanas, do que ingressar no mercado formal e perder o benefício.

Diante dessa conjuntura, a renda básica surge como um modelo abrangente, que não impõe condicionalidades e é universal, ou seja, é direito inerente a todos os cidadãos de uma comunidade política. 
A renda básica apresenta potenciais maiores para diminuir a desigualdade social, além de ser progressiva, atingindo valores maiores e proporcionando meios para os cidadãos encontrarem melhores condições de vida, afasta, pelo seu caráter universal, o estigma da pobreza. O valor da renda básica deve ser suficiente para prover o necessário para que todos tenham condições de viver em condições dignas, proporcionando mais autonomia e liberdade.

No Brasil foi aprovada em 2004 a lei 10.835/04, Lei da Renda Básica de Cidadania, apresentada em 2001 pelo senador Eduardo Suplicy. A mesma dispõe que a renda básica de cidadania será implementada por etapas, progressivamente, uma particularidade em relação ao conceito de universalidade, mas compreensível por conta do contingente populacional e poucas perspectivas orçamentárias para a implementação imediata a todos.

A renda básica pode vir a cumprir com a norma programática constitucional prevista no artigo $3^{\circ}$, a qual determina como objetivo da República Federativa Brasileira a construção de uma sociedade livre, justa e solidária, a diminuição da pobreza e das desigualdades sociais e regionais. No entanto, o que ficou evidente é que até o presente momento foram implementados somente programas burocráticos, os quais não atingem o objetivo de forma abrangente e eficiente, acabando por refletir ainda mais o problemático quadro político econômico brasileiro. Trata-se de um contexto em que o país tem elevado número de pobreza e políticas públicas ineficientes, as quais excluem um grande número de pessoas devido aos requisitos que burocratizam os programas, concluindo-se, portanto, que a Renda Básica de Cidadania seria uma forma mais eficiente no combate às desigualdades devido ao seu caráter universal.

A regulamentação e implementação da Renda Básica de Cidadania aparece como uma expectativa de transição entre o Programa Bolsa Família para Renda Básica de Cidadania. As possibilidades de que a Renda Básica de Cidadania seja implementada em um futuro próximo se maximizam em um cenário de crise e instabilidades, onde a atuação estatal e os conceitos de solidariedade demonstram ser a solução para que a justiça e paz social sejam concretizadas mostrando como a Renda Básica de Cidadania se constitui num instrumento fundamental para se assegurar liberdade real para todos os seres humanos.

Porém, a renda básica de cidadania não caminha sozinha. Ela pretende transferir renda e garantir uma igualdade básica para todos, porém o acesso aos serviços públicos deve ser expandido e a qualidade deles deve ser melhorada. Ou seja, o Estado deve atuar em vários setores de forma articulada, para que seja possível maior eficácia da renda básica de cidadania, e, portanto, maior desenvolvimento social. 


\section{REFERÊNCIAS}

ADAS, Melhem. A fome: crise ou escândalo. $17^{\mathrm{a}}$ Ed. São Paulo: Moderna, 1988.

BOBBIO, Norberto. Teoria geral da política: a filosofia política e as lições dos clássicos. Versão traduzida por Daniela Beccaria Versiane. Rio de Janeiro: Editora Elsevier, 2000 .

BRASIL. Constituição da República Federativa do Brasil: promulgada em 5 de outubro de 1988. Disponível em: http://www.planalto.gov.br/ccivil_03/Constituicao/Constituicao.htm.

CARDOSO, Fábio Luiz Lopes. Da renda mínima à renda básica de cidadania. Disponível em:http://repositorio.unicamp.br/bitstream/REPOSIP/278726/1/Cardoso_FabioLuizLopes_M.pdf

DIAS, Reinaldo. Políticas públicas: princípios, propósitos e processos. São Paulo: Atlas, 2012.

DYE, Thomas. Undertanding public policy. Englewwod Cliffs, NJ: Prentice-Hall, 1972.

FERREIRA, Leonardo Teodoro. Auxílio Emergencial: Uma via expressa para a Renda Básica Universal? Disponível em: https://diplomatique.org.br/uma-via-expressa-para-a-renda-basica-universal/

GALEANO, Eduardo. As veias abertas da América Latina. Tradução de Sérgio Faraco. Porto Alegre: L\&PM, 2012.

GIL, Antônio Carlos. Como elaborar projetos de pesquisa. 4 ed. São Paulo: Atlas, 2002.

GONZALEZ, Lauro e LOTTA, Gabriela. Erros de gestão podem deixar 6 milhões de famílias sem auxílio na pandemia. Folha de S. Paulo. Disponível em: https://www1. folha.uol.com.br/mercado/2020/09/erros-de-gestao-podem-deixar-6-milhoes-de-familias-sem-auxilio-na-pandemia.shtml

GRINOVER, Ada Pellegrini e WATANABE, Kazuo. o controle jurisdicional de políticas públicas. $2^{\mathrm{a}} \mathrm{Ed}$. Rio de Janeiro: Forense, 2013.

GUILHERME, ROSILAINE CORADINI. Renda mínima de inserção e transferência condicionada de renda: as (a) simetrias entre União Europeia e MERCOSUL. Disponível em: http://repositorio.pucrs.br/dspace/handle/10923/8378 .

HOWLeTt, Michael, RAMESH, M., PERL, Antonhy. Política Pública: seus ciclos e subsistemas: uma abordagem integradora. Rio de Janeiro: Elsevier, 2013.

IANNI, Octavio. 0 Colapso do populismo no Brasil. $4^{\circ}$ ed. Rio de Janeiro: Civilização Brasileira, 1988. 
JUNIOR, Osvaldo Canela. Controle Judicial de Políticas Públicas. São Paulo: Saraiva, 2011.

LAKATOS, E. M.; MARCONI, M. de A. Técnicas de pesquisa: planejamento e execução de pesquisas, amostragens e técnicas de pesquisas, elaboração, análise e interpretação de dados. Ed. 4. São Paulo: Atlas, 1999.

LICIO, Elaine Cristina. A trajetória dos programas de renda mínima e bolsa escola no brasil: o impacto da variável federativa. Disponível em: http://bibliotecadigital. fgv.br/dspace/handle/10438/5247 .

MENEZES, Francisco e SANTARELLI, Mariana. o bolsa família Funciona? . Disponível em: https://diplomatique.org.br/o-bolsa-familia-funciona/

MORE, Thomas. Utopia - Versão traduzida por Anah de Melo Franco. Brasilia: Universidade de Brasilia, 2004.

OLSON, Mancur. A lógica da ação coletiva. São Paulo: Edusp, 1999.

QUINALHA, Renan Honório. Justiça de transição: contornos do conceito. São Paulo: Outras Expressões, 2013.

SECCHI, Leonardo. Políticas Públicas: conceitos, esquemas de análise, casos práticos. $2^{\mathrm{a}}$ Ed. São Paulo: Cengage Learning, 2013.

SILVA, Natália Andrade Machado. Programa Bolsa Família: Impactos e desafios no enfrentamento à pobreza no Brasil. Disponível em https://app.uff.br/riuff/bitstream/1/5222/1/TCC\%20NAT\%C3\%81LIA.pdf .

SUPLICY, Eduardo Matarazzo. Renda de Cidadania: a saída é pela porta. $7^{\mathrm{a}} \mathrm{Ed}$. São Paulo: Cortez, 2013.

SUPLICY, Eduardo Matarazz. Renda Básica: Renda Mínima Garantida para o século XXI?. $5^{\text {a }}$ Ed. São Paulo: Cortez, 2002.

VAN PARJIS, Philippe. Capitalismo de renda básica. In: Lua Nova, nº 32, abril, 1994. 